\title{
Effect of Surface Modification of Acetabular Cup with Embedded Micro-Pits on Friction Properties
}

\author{
S. Syahrullail ${ }^{1}$, N. Sapawe ${ }^{1, *}$, M.D. Razak $^{1}$, Y. Azli ${ }^{2}$ \\ ${ }^{1}$ Transportation Research Alliance, Department of Thermo-Fluids, Faculty of Mechanical Engineering, Universiti Teknologi Malaysia, \\ 81310 UTM Johor Bahru, Johor, MALAYSIA \\ ${ }^{2}$ Department of Biotechnology and Medical Engineering, Faculty of Biosciences and Medical Engineering, Universiti Teknologi \\ Malaysia, 81310 UTM Johor Bahru, Johor, MALAYSIA \\ *Corresponding author: norzahirspawe@gmail.com
}

Received August 28, 2014; Revised September 18, 2014; Accepted September 29, 2014

\begin{abstract}
This study describes an investigation of the effect on friction when an acetabular cup surface is embedded with micro-pits. The micro-pit is potentially a suitable structure to act as a lubricant reservoir, in order to reduce the level of friction present between the surfaces of a hip prosthesis. The experiments were carried out using a modified four-ball tribometer. Refined, Bleached and Deodorised (RBD) palm olein and additive-free paraffinic mineral oil were selected to provide lubrication. When the palm olein was applied to the acetabular surface, friction in the hip implant decreased. Severe damage on the acetabular surface resulted in lubricant-free test conditions. Meanwhile, the results of tests on the acetabular cup, with 10 to 40 embedded micro-pits on the surface, indicated that friction had decreased. Based on the experiments, surface modification of the acetabular cup with embedded micro-pits, could prolong the biomechanics of hip prostheses.
\end{abstract}

Keywords: acetabular cup, micro-pits, modification, friction, bio-lubricant, palm oil

Cite This Article: S. Syahrullail, N. Sapawe, M.D. Razak, and Y. Azli, "Effect of Surface Modification of Acetabular Cup with Embedded Micro-Pits on Friction Properties.” American Journal of Mechanical Engineering, vol. 2, no. 5 (2014): 125-129. doi: 10.12691/ajme-2-5-1.

\section{Introduction}

Joint dislocation after hip replacement is one of the risks and a complication of metal-on-metal (MoM) resurfacing $[1,2,3]$. The main problem in the acetabular and femoral head is damage caused by friction and wear $[2,4,5]$. In hip implant tribology, a reduction of synovial fluid to lubricate the hip prosthesis leads to unsatisfactory outcomes, and even failure of the implant [6,7]. Undergoing a total hip arthroplasty (THA) operation can be traumatic for the patient and, in general, is a very expensive intervention $[8,9,10,11]$. Therefore, optimising the surface contact between the femoral head and the acetabular cup is likely to extend the lifespan of the hip prosthesis, and promote better quality of life for patients $[12,13,14,15]$. Studying the acetabular cup surface can be challenging for researchers, and many studies in the past have concentrated on investigating the kinematics and biomechanics of the hip [16,17]. The main purpose of many of those earlier studies was to reduce the high cost of hip replacement.

In this study, acrylonitrile butadiene styrene was used to mold an acetabular cup which was embedded with micro-pits. Palm olein was selected as the bio-lubricant, because it has very good viscosity. During assessment of the hip implant prototype, the lubrication characteristics between the weight-bearing femoral head and the acetabular cup were formulated using the Hamrock and
Dowson equation [18]. Stribeck analysis was also used to evaluate data that resulted from an investigation of the modes of friction, and to correlate the significance of surface modification to the acetabular cup, the lubricant applied, and the frictional torque present in the cup.

This study has focused on improving the normal acetabular cup design, by embedding micro-pits in the surface of the cup, to increase the lifespan. An in-depth comparison was made of the level of friction on the normal cup and if there was any change after surface modification with micro-pits. The potential effectiveness of the revised design was examined by measuring the friction, wear, and the influence of the lubricant. The acetabular cup with micro-pits was investigated by screening the hip implant, using a modified four-ball tribometer. In addition, the suitability of palm olein, which does not contain proteins, was identified as a potential biolubricant to reduce friction and hip wear.

\section{Experimental}

\subsection{Materials}

A pin on disc tribometer for screening friction and wear in metal-on-metal implants was used to screen the hip implants. Titanium, which has a density of $4.54 \mathrm{~g} / \mathrm{cm}^{3}$, was the material selected for the experiments. The stationery pin had a diameter of $8 \mathrm{~mm}$ and was $30 \mathrm{~mm}$ long. Abrasive sandpaper, with the grain size of $1000 \mu \mathrm{m}$, 
was used to smooth the disc after the completion of each experiment. This was to ensure that no particles or debris remained trapped between the disc and pin. The surface textures of the pin and disc were evaluated by examining their profiles. A new pin was used for each experiment and it was cleaned with acetone before the experiment began. A four-ball tribometer apparatus had been modified into a single ball bearing, to simulate the femoral head as the contact point on the curved surface of the acetabular cup. These types of screening tests are used to conduct accelerated protocols that simulate particularly extreme conditions, to predict the performance limits of materials.

\subsection{Micro-pits Procedure}

In this study, the acetabular cup had clusters of between 10 and 40 micro-pits on the surface. During the experiment, friction was calculated using a tribometer, with the acetabular liner oriented to the femoral head. There was a significant decrease in friction because of the micro-pits and when using a lubricant. The data obtained from the testing, indicated that micro-pits embedded into acetabular surfaces, have the potential to reduce wear in hip prostheses.

\subsection{Friction and Wear Evaluation}

In order to understand the variations in friction and wear, a grooved disc was used. The experiments were carried out over a specified time period, and with the same amount of lubricant placed on the surface between on pin and disc. The lubricant was applied between the surfaces by manually dripping it onto the modified disc, which had a $10 \mathrm{~mm}$-wide groove with a depth of $5 \mathrm{~mm}$. This construction was to prevent the palm olein from escaping as the disc rotated, especially at high speed. During the experiment, the wear track was adjusted by releasing and re-fixing the sliding plate, positioned at $70 \mathrm{~mm}$.

\subsection{Surface Profile}

The surfaces of the pin and disc were measured before and after the experiment, by examining roughness profiles (Mitutoyo SJ-210). A stylus tip was used to evaluate the surface patterning. The surfaces of the discs were unidirectional before the experiments, smoothed by using abrasive paper to a surface finish of arithmetic roughness value $R_{\mathrm{a}},=0.4 \pm 0.1 \mu \mathrm{m}$.

\subsection{Lubricants}

The lubricity of the RBD palm olein was compared to the performance of the paraffinic mineral oil. The amount of each lubricant used was approximately $5 \mathrm{ml}$, and the density and viscosity of the oils were measured using a viscometer at temperature levels ranging from 40 to $100^{\circ} \mathrm{C}$. The results are shown in Table 1 .

Table 1. Properties of different types of lubricating oil

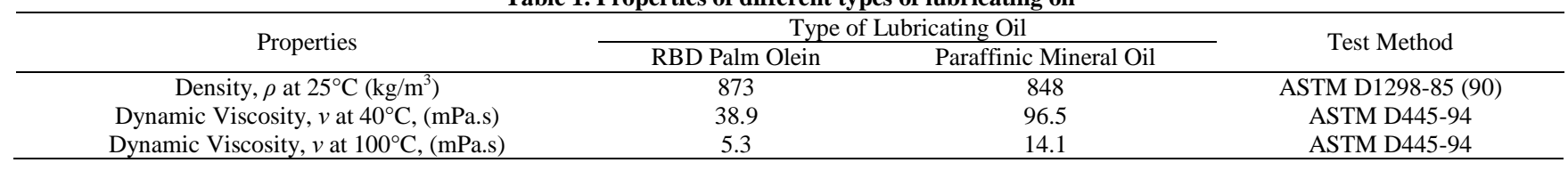
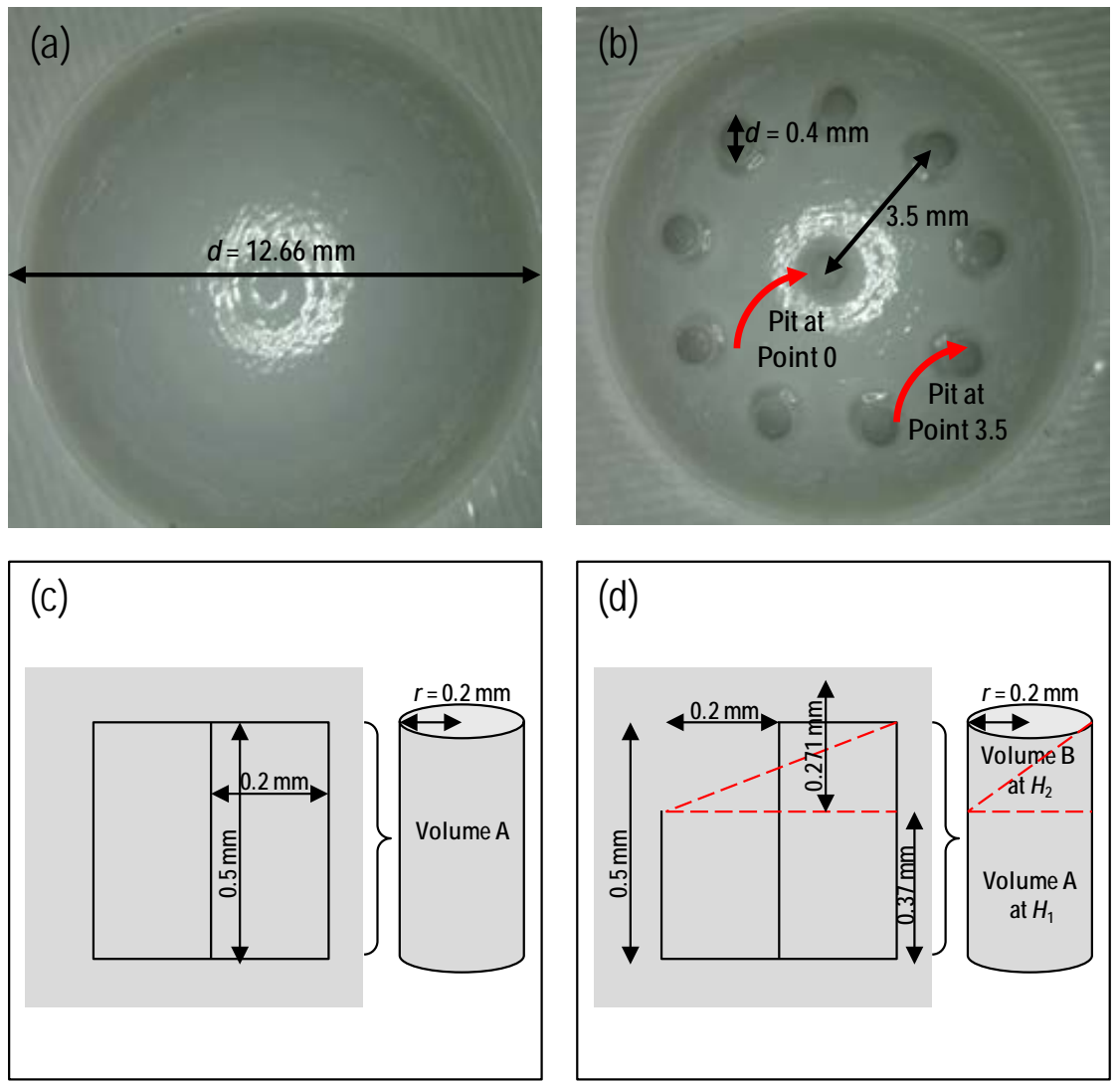

Figure 1. Acetabular cup with (a) no pits (b) 10 pits, and a schematic of micro-pits at (c) point 0 (d) point 3.5 from the centre 


\section{Results and Discussion}

\subsection{Micro-pits Evaluation}

The dimensions of the acetabular cup are shown in Figure 1. It had a diameter of $25 \mathrm{~mm}$ and the curve at the centre had a radius of $6.33 \mathrm{~mm}$. Each of the micro-pit cavities on the surface had a diameter of $0.4 \mathrm{~mm}(r=0.2$ $\mathrm{mm})$. According to Figure $1 \mathrm{a}$ and $1 \mathrm{~b}$, one micro-pit was placed at point 0 at the centre, and nine micro-pits were placed at points $3.5 \mathrm{~mm}$ surrounding the centre. The schematic illustrations in Figure 1c and 1d show the positions of the micro-pits. Studies suggest that each micro-pit has volumetric properties, which extend the total radius of the acetabular surface. By applying equation 1 (the Hamrock and Dowson equation), the effect of modifying the surface of the acetabular can start to be evaluated.

$$
\frac{1}{R}=\frac{1}{R_{1}}-\frac{1}{R_{2}}
$$

Where, $R$ is the equivalent radius using the Hamrock and Dowson equation (i.e. no micro-pits on the surface), and $R_{1}$ and $R_{2}$ represent the femoral head and acetabular cup respectively.

In this study, however, there are modifications on the acetabular surface, and therefore an increased value of $R_{2}$, may affect the results of equation 1. Mathematically, the concept of a surface-volume increase was used to determine the total of $R$ in the following equations.

$$
\begin{aligned}
\text { Volume }_{A} & =\pi r^{2} h \\
\text { Volume }_{B} & =\frac{1}{2} \pi r^{2} h
\end{aligned}
$$

Where, A and B are the volume of oil that is trapped in the micro-pit.

The effect of the micro-pit modifications on the normal acetabular is therefore calculated based on equation 1 . The calculated value of the volumetric properties of the micropits is shown in Table 2. Based on these values, the assumption is that the sum of the volumes of the micro-pit designs can be determined using equations 2 and 3 . Therefore, the total additional volume of a surface embedded with 10 and 40 micro-pits, can be calculated using equations 4 and 5 , where the equivalents of the formulas are $6.37 \times 10^{-4} \mathrm{~m}^{3}$ and $2.56 \times 10^{-3} \mathrm{~m}^{3}$ respectively.

$$
\begin{gathered}
V_{10 \text { pits }}=V_{\mathrm{a} 1}+V_{\mathrm{c} 9} \\
V_{40 \text { pits }}=V_{\mathrm{b} 8}+V_{\mathrm{c} 16}+V_{\mathrm{d} 16}
\end{gathered}
$$

Where, $V_{10 \text { pits }}$ and $V_{40 \text { pits }}$ represent the total volume for

\begin{tabular}{|c|c|c|c|c|c|}
\hline \multirow{2}{*}{ Parameter } & \multicolumn{5}{|c|}{ Micro-pits } \\
\hline & 0 & 10 & 12 & 24 & 40 \\
\hline Equivalent radius, $R(\mathrm{~m})$ & 13.4 & $2.69 \times 10^{-1}$ & $2.40 \times 10^{-1}$ & $1.71 \times 10^{-1}$ & $1.41 \times 10^{-1}$ \\
\hline Lubricant viscosity, $\eta$ (Pa.s) & $3.79 \times 10^{-2}$ & $3.79 \times 10^{-2}$ & $3.79 \times 10^{-2}$ & $3.79 \times 10^{-2}$ & $3.79 \times 10^{-2}$ \\
\hline Young's modulus, $E$ ' $(\mathrm{Pa})$ & $2.30 \times 10^{9}$ & $2.30 \times 10^{9}$ & $2.30 \times 10^{9}$ & $2.30 \times 10^{9}$ & $2.30 \times 10^{9}$ \\
\hline Load, $L(\mathrm{~N})$ & 400 & 400 & 400 & 400 & 400 \\
\hline Entraining velocity, $u$ (m.s-1) & 70.2 & 1.41 & $5.91 \times 10^{-1}$ & 1.01 & $7.17 \times 10^{-1}$ \\
\hline Film thickness, $h_{\min }(\mu \mathrm{m})$ & $7.24 \times 10^{-4}$ & $2.83 \times 10^{-6}$ & $2.41 \times 10^{-6}$ & $1.49 \times 10^{-6}$ & $1.13 \times 10^{-6}$ \\
\hline Ratio, $\lambda$ & $>3$ & $>3$ & $>3$ & $>3$ & $>1$ \\
\hline Sommerfeld number, $S$ & 50.5 & $1.50 \times 10^{-2}$ & $1.21 \times 10^{-2}$ & $6.17 \times 10^{-3}$ & $4.19 \times 10^{-3}$ \\
\hline Coefficient of sliding friction, $\left(u_{k}\right)$ & $1.77 \times 10^{-3}$ & $8.01 \times 10^{-5}$ & $1.61 \times 10^{-5}$ & $1.63 \times 10^{-5}$ & $2.69 \times 10^{-5}$ \\
\hline
\end{tabular}
10 micro-pits and 40 micro-pits, respectively.

Table 2. Calculations of micro-pit volumetrics

\begin{tabular}{cccccccc}
\hline Pit at point $(\mathrm{mm})$ & $R_{1}(\mathrm{~m})$ & $H_{1}(\mathrm{~m})$ & Volume A, $V_{\mathrm{A}}\left(\mathrm{m}^{3}\right)$ & $R_{2}(\mathrm{~m})$ & $H_{2}(\mathrm{~m})$ & ${\text { Volume B, } V_{\mathrm{B}}\left(\mathrm{m}^{3}\right)}^{\text {Total volume, } V_{\mathrm{A}}+V_{\mathrm{B}}\left(\mathrm{m}^{3}\right)}$ \\
\hline 0 & 0.02 & 0.050 & $6.28 \times 10^{-5}$ & 0 & 0 & 0 & $6.28 \times 10^{-5}$ \\
2 & 0.02 & 0.044 & $5.48 \times 10^{-5}$ & 0.02 & 0.014 & $8.48 \times 10^{-6}$ \\
3.5 & 0.02 & 0.037 & $4.65 \times 10^{-5}$ & 0.02 & 0.027 & $1.70 \times 10^{-5}$ \\
5 & 0.02 & 0.025 & $3.14 \times 10^{-5}$ & 0.02 & 0.053 & $3.35 \times 10^{-5}$ \\
\hline
\end{tabular}

Table 3. Properties of micro-pits tested at $40 \mathrm{rev} / \mathrm{min}$

\subsection{Study of the Prototype of Acetabular Cup}

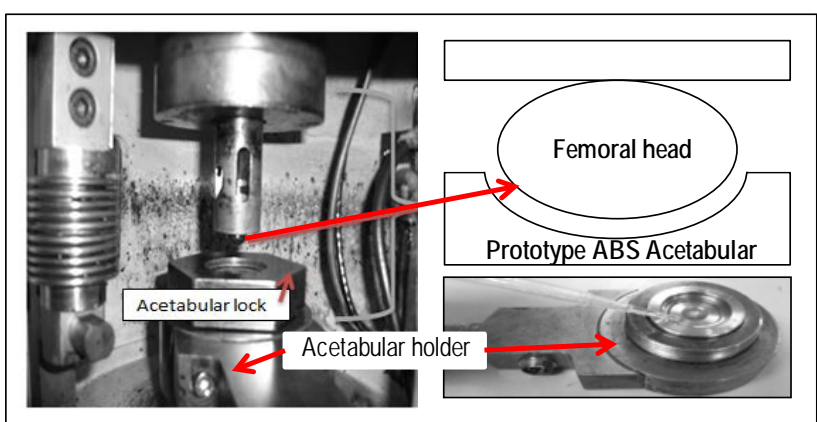

Figure 2. Modification of four-ball tribotester for hip screening

Many earlier researches were developed primarily to simulate or predict the future effectiveness of a particular methodology. In the current context, hip screening can be used to conduct accelerated protocols that are able to replicate or simulate effects, particularly in extreme conditions, and to establish the performance limits of experimental materials used. The modified four-ball tester to screen hip state-of-the-art hip joint simulations is described in Figure 2. However, the work piece in the current study was a hip prosthesis prototype prepared in ABS, with different amounts of micro-pits on the acetabular surface, and the combination of material, surface designs and lubricant were subjected to testing by the modified tribometer.

The results of the tests carried out on the prototype with the number of embedded micro-pits ranging from 0 to 40 pits are shown in Table 3 . The minimum parameters of lubricant film thickness $\left(h_{\min }\right)$ were calculated based on the Hamrock and Dowson equation $(R)$, which is expressed in equation 6 .

$$
h=2.798 R\left(\frac{\eta u}{E^{\prime} R}\right)^{0.65}\left(\frac{L}{E^{\prime} R^{2}}\right)^{-0.21}
$$


Where, $\eta$ is the viscosity of the palm oil at $40{ }^{\circ} \mathrm{C}, u$ is the entraining velocity, $E$ ' is the effective elastic modulus of $\mathrm{ABS}, R$ is the equivalent radius of the ball--on-plane model, and $L$ is the load.

In addition, the Sommerfeld number was also determined using equation 7 , to define the properties of the lubricant.

$$
S=\left(\frac{r}{C}\right)^{2} \frac{\mu N}{P}
$$

Where, $S$ is the Sommerfeld number or bearing characteristic, $r$ is the shaft radius, $c$ is the radical clearance, $\mu$ is the viscosity of the lubricant, $N$ is the speed of the rotating shaft, and $P$ is the load per unit of projected bearing area.

The calculation of the equivalent radius is based on the modification of $R$ by the Hamrock and Dowson equation. The different $R$ value may affect the Sommerfeld number, and the coefficient of friction in each experiment. Figure 3 shows the frictional torque is gradually reduced as more embedded micro-pits are present.

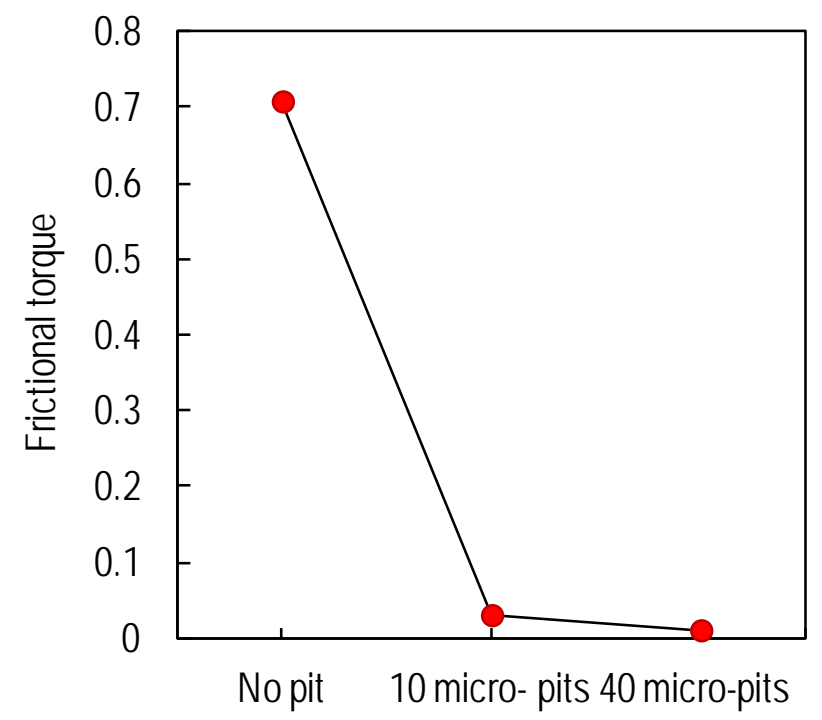

Figure 3. Frictional torque at different micro-pit densities

\subsection{Investigation on the lubrication regimes (Stribeck curves)}

For each experiment, a Stribeck curve was plotted to examine the performance and investigate the lubrication regimes when palm oil was used as the lubricant. To be able to construct the Stribeck curves, the modified fourball tribometer was used to examine each acetabular cup sample embedded with 10 and 40 micro-pits. The tribology of the hip implant models were tested with a 40 newton load factor, using the palm oil lubricant. The frictional torque was evaluated and the Stribeck analysis enabled a representation of the lubrication regimes to be developed for each experiment. It was observed that implants with a smaller ball radius had lower friction, boundary, and mixed lubrication regimes. However, implants with a larger ball radius, showed only boundary lubrication.

Although both the Stribeck curves shown in Figure 4 are similar, there is a difference in the range shape for the experiment, showing at mixed lubrication the lubricant is too thin and the gradient from boundary to mixed lubrication is too pronounced. When the Sommerfeld number was low, the coefficient of friction was observed at 0.00177 . The curve demonstrates the sensitivity of the Sommerfeld number factor, which is representative of the mixed lubrication regime, and is affected by the way in which the lubricant behaves. In the other words, the experiments on acetabular cups with embedded micro-pits, showed a significant decrease in friction. However, there may be a threat of dislocation when a larger number of micro-pits are added. This raises the importance of the density of embedded micro-pits, and the need to reevaluate the parameters, in order to negate potential loosening of the hip implant, even though a low level of friction is achieved.. Furthermore, the friction between the femoral head and the acetabular cup may be reduced by using other potential lubricants $[6,7,19]$. However, surface modification of the acetabular cup with micro-pitting, does play a role in reducing friction.

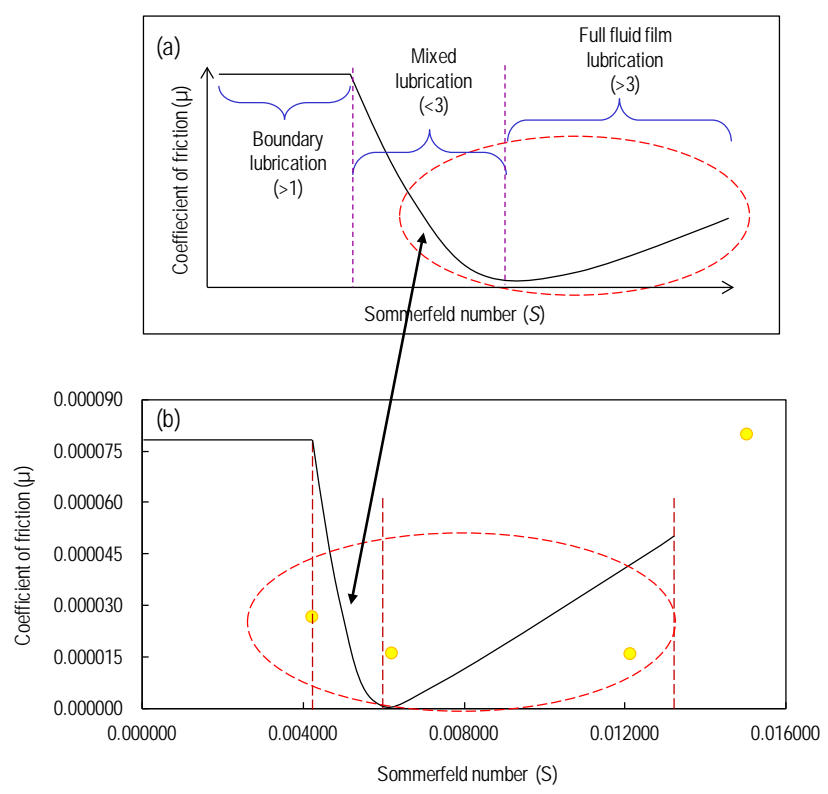

Figure 4. Stribeck curve of results (a) theoretical (b) experimental

Much research has explored the effectiveness of lubricant films, which have been characterised by film thickness, which is dependent on the viscosity of the lubricant, the velocity of surface contact, the load across the interface, and the surface roughness [20,21,22,23]. The relevance of the findings reinforces how surface modification with micro-pits can alleviate problems associated with friction in various biomedical applications.

\subsection{Analysis of the Lambda Ratio, $\lambda$}

A theoretical analysis of the mode of lubrication can be carried out by calculating the lambda ratio $(\lambda)$ of the lubricating film thickness in hip prostheses to the composite surface roughness of the femoral head and acetabular cup. A value of $\lambda>3$ indicates that full fluidfilm lubrication has probably been established in the joint, and the fluid-film thickness is greater than the asperity heights on the articular surface. The mixed lubrication regime indicated a lambda ratio between one and three, and the boundary lubrication ratio was $\lambda \leq 1$. In general, as the lambda ratio increases, wear decreases in MoM 
joints, and the joints are operating under boundary and full fluid-film lubrication, which have the highest and lowest wear rates respectively. The lubrication between the bearing surfaces of hip implants containing embedded micro-pits and the effect on friction generated during articulation, is normally illustrated by a Stribeck curve, which in conjunction with this study has been described in Figure 4.

\section{Conclusions}

In this study, the innovative approach of forming micro-pits on the surface of the acetabular cup, and applying palm olein as the lubricant, were subjected to detailed investigation. The results of the analysis of the surface-modified acetabular cup showed that friction torque was reduced, which is a positive indication for prolonging the lifespan of hip prostheses. An extremely low level of friction was achieved, when the surface of the acetabular contained micro-pits. The modification of the acetabular demonstrates that it is important to consider the risk of increasing hip dislocation in THR recipients. Experiments were carried out to evaluate performance when there were no pits, and the use of 10 and 40 micropits. The results have been described comprehensively, and the significance of the results warrants further study. They could develop more understanding of the relevance of micro-pit volumes and densities, and lead to improved acetabular cup designs.

\section{Acknowledgement}

The authors are grateful for the financial support of a Research University Grant (RUG) from Universiti Teknologi Malaysia (UTM) (GUP-03H58), the Fundamental Research Grant Scheme (FRGS-4F229) provided by the Malaysian Ministry of Higher Education (MOHE), an E-Science Fund Grant and the Exploratory Research Grant Scheme (ERGS) facilitated by the Ministry of Science, Technology and Innovation (MOSTI), Malaysia, the award of a UTM Research Management Centre Postdoctoral Fellowship (Norzahir Sapawe), and last, but not least, for the support of the Faculty of Mechanical Engineering at UTM.

\section{References}

[1] M. Pettersson, T. Berlind, S. Schmidt, S. Jacobson, L. Hultman, C. Persson, H. Engqvist, Surf. Coat. Technol. 235 (2013) 827-834.

[2] S. Williams, D. Jalali-Vahid, C. Brockett, Z. Jin, M.H. Stine, E. Ingham, J. Fisher, J. Biomechanics 39 (2006) 2274-2281.

[3] J. Huang, S. Wan, B. Liu, Q. Xue, Surf. Coat. Technol. 247 (2014) 20-29.

[4] Y.S. Liao, D. McNulty, M. Hanes, Wear 255 (2003) 1051-1056.

[5] P. Moghadas, A. Mohamed, D.W.L. Hukins, D.E.T. Shepherd, J. Biomechanics 45 (2012) 504-509.

[6] Q.T. Nguyen, B.L. Wong, J. Chun, Y.C. Yoon, F.E. Talke, R.L. Sah, J. Biomechanics 43 (2010) 1787-1793.

[7] S.M.T. Chan, C.P. Neu, K. Komvopoulos, A.H. Reddi, J. Biomechanics 44 (2011) 2015-2020.

[8] J.J. Elsner, Y. Mezape, K. Hakshur, M. Shemesh, E. Linder-Ganz, A. Shterling, N. Eliaz, Acta Biomaterialia 6 (2010) 4698-4707.

[9] J.E. Hsu, S.D. Kinsella, J.P. Garino, G.C. Lee, Seminars in Arthroplasty 22 (2011) 229-233.

[10] H. Koseki, H. Shindo, K. Baba, T. Fujikawa, N. Sakai, Y. Sawae, T. Murakami, Surf. Coat. Technol. 202 (2008) 4775-4779.

[11] C. Balagna, M.G. Faga, S. Spriano, Mater. Sci. Eng. C: Mater. Biol. Appl. 32 (2012) 887-895.

[12] A.S. Dickinson, A.C. Taylor, M. Browne, J. Biomechanics 45 (2012) 719-723.

[13] A. Holzer, C. Schroder, M. Woiczinski, P. Sadoghi, P.E. Muller, V. Jansson, J. Biomechanics 45 (2012) 602-604.

[14] H. Liu, Y. Leng, J. Tang, S. Wang, D. Xie, H. Sun, N. Huang, Surf. Coat. Technol. 206 (2012) 4907-4914.

[15] S. Syahrullail, D.M. Razak, N. Sapawe, Y. Azli, N. Kartiko, Appl. Mech. Mater. 554 (2014) 401-405.

[16] V. Camomilla, A. Cereatti, L. Cheza, A. Cappozzo, J. Biomechanics 46 (2013) 625-630.

[17] T.Y. Tsai, J.S. Li, S. Wang, H. Lin, J. Biomechanics 46 (2013) 1300-1304.

[18] B.J. Hamrock, D. Dowson, J. Lubrication Technol. 101 (1979) 9298.

[19] D. Wu, Y. Liu, S. Yang, Z. Yang, H. Tang, Wear 294-295 (2012) 370-379.

[20] M.G. Holthaus, L. Treccani, K. Rezwan, J. European Ceram. Soc. 31 (2011) 2809-2817.

[21] L. Mattei, F. Di Puccio, B. Piccigallo, E. Ciulli, Tribol. Int. 44 (2011) 532-549.

[22] C. Myant, R. Underwood, J. Fan, P.M. Cann, J. Mech. Behavior Biomed. Mater. 6 (2012) 30-40.

[23] A. Ramesh, W. Akram, S.P. Mishra, A.H. Cannon, A.A. Polycarpou, W.P. King, Tribol. Int. 57 (2013) 170-176. 